\title{
Integrating the
}

Science of Learming

and Development

into Teacher Education

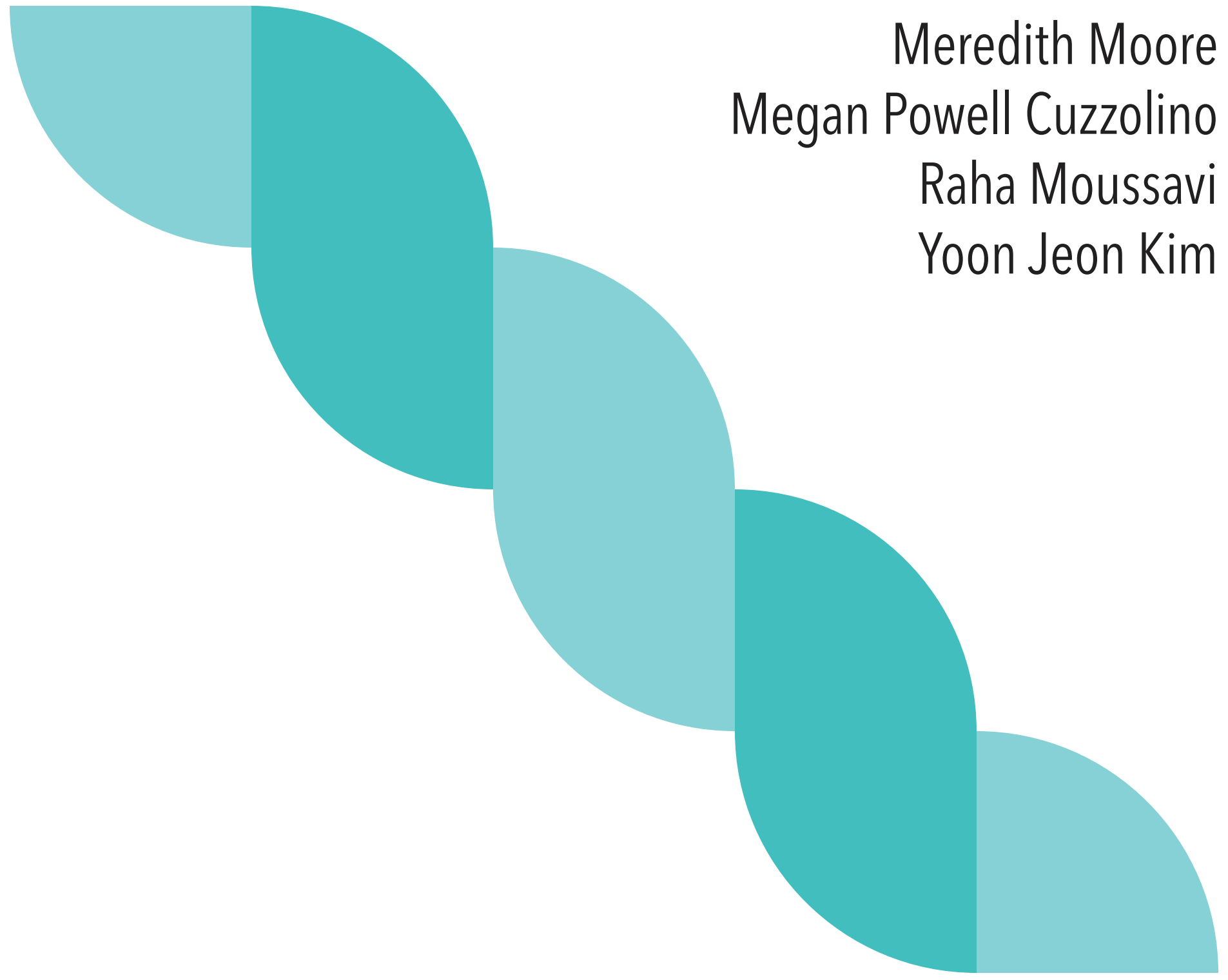




\section{IIIIII PLAYFULJOURNEYLAB

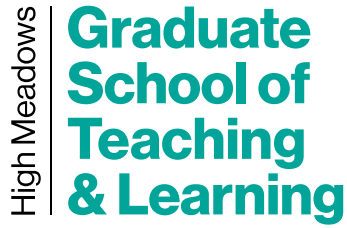

The MIT Playful Journey Lab was created by researchers and designers with a passion for playful assessment and learning. We are embarking on a journey to develop emerging technologies as well as non-digital tools to better understand, design, and use innovative approaches that will prepare individuals to participate in 21st century economies. The lab is founded on the belief that these technologies and approaches, supported by research-backed playful learning and assessment practices, are an important tool for empowering learners, and are necessary for designing a lifelong and lifewide education system that prepares individuals to learn throughout their lives-across school, work, and interest-driven contexts.

For more information about the Playful Journey Lab, visit us online at playful.mit.edu or follow us on Twitterat @PlayfulMIT

The High Meadows Graduate School of Teaching and Learning (HMGSTL), formerly the Woodrow Wilson Graduate School of Teaching and Learning, was established through a collaboration between the Woodrow Wilson National Fellowship Foundation and the Massachusetts Institute of Technology to reinvent American teacher education for the 21st century. As an operational innovation lab, the HMGSTL simultaneously prepares teachers through its competency-based program and works to transform the existing model of teacher education by designing, piloting, launching, and scaling innovations in teacher preparation. The HMGSTL prepares educators to thrive in today's classrooms and to move those classrooms into the future.

For more information about the High Meadows Graduate School of Teaching and Learning, visit hmgradschool.org.

We would like to thank the faculty and staff of the High Meadows Graduate School of Teaching and Learning and additional colleagues who offered guidance and feedback throughout the development of this paper and the curriculum integration process. We are particularly indebted to Manjula Karamcheti, Dr. Dessalines (Des) Floyd, Dr. Connie Shui-Yi Chow, Dr. Anjali Deshpande, Dr. Julianna Stockton, Dr. Raquel Saenz, Susan Balboni, Dr. Pei Pei Liu, and Dr. Linda Darling-Hammond. Peter Kirschmann produced the graphic design for the final version of this paper. 


\section{Introduction}

In the past few decades, knowledge of human learning and development has proliferated rapidly (Darling-Hammond et al., 2020; National Academies of Sciences, Engineering, and Medicine, 2018). New insights come from multiple fields, including neuroscience and biology, sociology, psychology, developmental science, and learning sciences, as well as applied educational research. As a whole, this growing body of research makes clear that children's learning and development are shaped by interactions among environmental factors, relationships, and learning opportunities, along with internal cognitive, psychological, physical, social, and emotional processes (Darling-Hammond et al., 2020). It suggests the need for a shift away from the traditional instructionist model that has long dominated schools, in which knowledge is treated as a collection of facts and procedures, the goal of schooling is thought to be the transmission of these facts and procedures into students' heads, and the job of a teacher is to transmit this information to their students (Sawyer, 2014).

Despite the broad-reaching implications of the science of learning and development $(\mathrm{SoLD})^{\mathrm{I}}$, many schools in the United States

I Throughout the paper, we employ the term "science of learning and development," or SoLD, rather than the more common "learning sciences," to highlight the importance of a whole child perspective on learning and development, wherein the child's physical, social-emotional, and psychological development continue to use traditional pedagogies and assessment models that are inconsistent with new research findings (Sawyer, 2014). Schools are notoriously slow to change. In fact, school policies are shaped by historical, economic, and demographic movements, just as much, if not more so, than advances in educational research (Hargreaves \& Goodson, 2006). We question the extent to which school reforms will effectively close the gap between SoLD research findings and current teaching and assessment approaches any time soon. We believe that teacher education provides a better alternative for bringing about change at the classroom level.

In this paper, we argue that teacher education should introduce SoLD findings to a new generation of teachers who will be positioned to use these findings in their own classrooms. Even though schools are slow to change at the institutional level, meaningful change can happen at the classroom level. Research has demonstrated that variation in student achievement is correlated with differences between teachers (Gordon et al., 2006; Hanushek \& Rivkin, 2012). Teachers within the same school-who teach the same grade and subject, and are accountable to the same standards-may nonetheless create different learning environments within their classrooms and use different pedagogical

are valued separately from and understood as inextricably linked to their academic and cognitive development. 
practices which lead to different outcomes for their students. We view teachers as intellectuals, who exercise judgment in the classroom (Zeichner, 2018). We believe that teachers should approach their work with an inquiry stance, treating their classrooms and schools as sites for investigation and experimentation (Cochran-Smith \& Lytle, 1999). Cochran-Smith and Lytle (1999) posit:

The knowledge teachers need to teach well is generated when teachers treat their own classrooms and schools as sites for intentional investigation at the same time that they treat the knowledge and theory produced by others as generative material for interrogation and interpretation. (p. 250)

We believe that SoLD research findings can be used as such "generative materials." The goal of grounding teacher education in SoLD is to support the development of teachers who can use this knowledge flexibly, attending to what matters most for the learning and development of their students while they adapt to the changing contexts in their schools and classrooms. One caveat is that teacher education must also help teacher candidates to understand the systemic nature of racism and other forms of oppression, explore education's role in perpetuating inequity, and interrogate their own positionality and biases (e.g. Bartolomé, 2004; Paris, 2016). Teachers who lack this kind of critical consciousness might put SoLD research findings to use in ways that reproduce injustice.

There are some efforts underway to introduce teacher candidates to research on learning and development. Darling-Hammond and colleagues (2019) highlight seven exemplary teacher education programs that prepare teachers for deeper learning, several of which support teachers to build a strong foundational understanding of learning and development. Other efforts focus specifically on integrating cognitive science research, such as the work Deans for Impacts, an educator preparation reform group, conducts with teacher education programs across the country to incorporate cognitive science insights. While such efforts are promising, they are limited in their reach. Many preservice preparation programs continue to offer inadequate coursework on social and emotional development, so that their graduates are unprepared to support students' development in these areas (Schonert-Reichl et al., 2015). Similarly, many programs are not yet preparing teacher candidates to understand cognitive development well enough to make instructional decisions that are consistent with research (Deans for Impact, 2020). Given these discouraging findings, we believe it is essential for the field of teacher education to have a conversation about integrating SoLD more widely. This paper seeks to spark that conversation.

In 2019, the Woodrow Wilson Graduate School of Teaching and Learning (WWGSTL) and MIT's Playful Journey Lab undertook a project with the goal of incorporating SoLD throughout the teacher education program. In this paper, we detail the steps we have taken so far, as well as those we plan to take in the future, to achieve our ultimate vision of teacher education grounded in SoLD. Our efforts to 
refine the program took us into uncharted territory. As little work has been done to systematically incorporate SoLD in teacher education, we had to develop our own processes for everything from selecting research to designing SoLD-focused learning experiences to supporting teacher educator learning. Since there are few existing resources for designing learning experiences and assessments of SoLD knowledge in teacher education, we created many new tools and resources. We benefited from having a dedicated learning designer involved at every stage of the project, which is not a model typically employed by teacher education programs. We believe that the processes and materials developed during this project can be a design resource for other teacher education programs, regardless of the scale of their efforts-from a complete redesign of an existing program to the integration of a particular SoLD topic in a course. Recognizing that every teacher preparation program is different, we do not offer our experiences as a blueprint for others to adopt. Rather, we use our experiences as illustrations to draw out lessons that we have learned that can be applied by other programs. Throughout the paper, we present takeaways that may be useful to other teacher preparation programs interested in integrating SoLD.

\section{Launching \\ a SoLD}

Integration Project

When the WWGSTL created an initial list of teaching competencies in 2016, it included a competency called "grounding instruction in the learning sciences." However, this body of research was not yet integrated into the curriculum when the master's program launched in 2018. Instead, teacher candidates engaged with SoLD through optional, stand-alone learning experiences, and a discrete module, completed towards the end of the program. The decision to redesign the program to make SoLD a pillar, rather than a mere add on, came about because faculty and staff, along with teacher candidates, observed a lack of program coherence during the 2018-2019 academic year. A group of faculty and staff recommended that the program designate a handful of competencies that are central to effective teaching as "core competencies," and make these central to the program, including setting a higher bar for competency. The full WWGSTL faculty, staff, and administration, along with Playful Journey Lab designers and researchers, engaged in a process of identifying the most important competencies from among the 20 competencies that teacher candidates were required to demonstrate. In consultation 
with teachers, school administrators, and teacher candidates, we selected "grounding instruction in the learning sciences" as one of five core competencies ${ }^{2}$. We recognized that the program would need to be redesigned so that teacher candidates would be supported to learn about, practice, and demonstrate core competencies at multiple times and in multiple contexts as they progress through the program.

To make this goal a reality, it was necessary to devote resources to the project, including people, time, and money. A SoLD team was designated to guide the process of integrating SoLD into the curriculum. The team consists of a learning scientist, a design researcher, and a learning designer with knowledge of the curriculum as a whole. This interdisciplinary team has the mix of skills and knowledge necessary to develop a SoLD plan that is well suited for the specific context of the WWGSTL. To further ensure programmatic coherence, the team has provided updates to and sought feedback from the complete faculty at multiple points throughout the process. This also provides an opportunity for faculty members to learn more SoLD, which is necessary for them to ultimately facilitate teacher candidate learning.

$2 \quad$ The five core competencies at the WWGSTL are: Thinking Like a Designer, Teaching for Justice, Grounding Practice in the Science of Learning and Development, Relating to Students, and Building a Community of Trust.

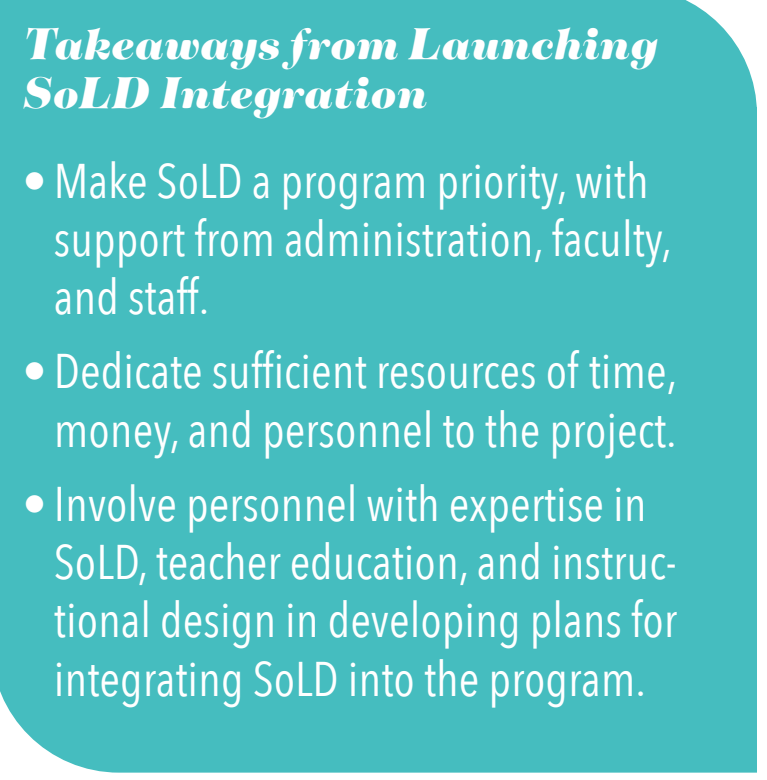

Takeaways from Launching

SoLD Integration

- Make SoLD a program priority, with

support from administration, faculty,

and staff.

- Dedicate sufficient resources of time, money, and personnel to the project.

- Involve personnel with expertise in

SoLD, teacher education, and instruc-

tional design in developing plans for integrating SoLD into the program. 


\section{Mapping the Territory}

The interdisciplinary nature of research on learning and development poses a challenge for teacher preparation programs, as integrating this research requires synthesizing a vast quantity of disparate literature (Darling-Hammond et al., 2020). Most teacher education programs do not have the bandwidth to synthesize all this research and are therefore dependent on others to distill the most important insights. In order to decide where to turn, and how to use resources created by other individuals or organizations, we believe that it is helpful to address two guiding questions at the outset of any work on integrating SoLD.

1. Which research on learning and development should be prioritized?

2. How should research findings from multiple fields be organized?

In the sections below, we describe how we answered these two questions, and what we learned along the way.

\section{Deciding on Priorities}

The learning sciences address big questions, such as: "What is learning and how does it occur? What 'should' people learn, and how do we know when they have learned it? What teaching methods, in which contexts, are most likely to bring about 'good' learning?” (Esmonde \& Booker, 2016, p. 1). Developmental science layers on additional questions about the influences of biology, psychology, and the environment on development. Scholars offer different answers to these questions, depending on their perspective, as the larger field of SoLD brings together scholarship from an individualistic, psychological tradition alongside research from situated and sociocultural traditions. As we began to sift through research syntheses in the learning sciences and the larger field of SoLD, we noted that authors emphasized different research findings, revealing differing perspectives on the nature of learning and development as well as the goals of schooling. We put these resources into conversation with the WWGSTL's values and operating assumptions about teaching, learning, and schooling, and used our perspectives to guide the selection of SoLD research.

The WWGSTL embraces a sociocultural perspective on learning and development. Broadly speaking, sociocultural theories explain the relationship between human action and the social, cultural, institutional, and historical situations in which it occurs (Wertsch et al., 1995). Sociocultural theorists hold individual learning as inseparable from context, emphasizing interrelationships between individuals and social worlds (Lave, 1996; Wenger, 2000). According to sociocultural theory, what the individual learns is influenced by, although not irreducible to, interactions with other people (Rafael et al., 2014). As patterns of interaction vary across cultures, learning is fundamentally a cultural process (Nasir et al., 2014). Some of the key propositions of sociocultural theory, which are supported by a significant body of empirical and 
theoretical work, include:

- Humans learn in different ways. There is no single, normative pathway.

- Central to human functioning are perceptions, emotions, social relationships and attachments, the need to address ego needs for a sense of safety, efficacy, health-as these are coordinated in human cognitive activity, activity that is situated, social, and dynamic.

- Humans belong to and participate in multiple cultural communities, communities that experience both stability and change, homogeneity and heterogeneity.

- Human functioning must be understood in the contexts of time (historical, ontogenetic, microgenetic) and as navigations within and across spaces. (Lee, 2016, pp. ix-x)

In accordance with our sociocultural perspective, we decided to prioritize the work of scholars such as anthropologists, sociologists, developmental scientists, educational researchers, and others who study learning and development in context.

The WWGSTL's vision and values also informed our decisions about which research to prioritize. The WWGSTL places a high value on community. The school's vision statement reads, "We need educators who will prepare their students to flourish in the economies of the future, and to develop in them the knowledge and skills to create just and caring communities and a sustainable world." The statement makes clear that the goal of schooling is much more than individual academic achievement. Thus, research on social and emotional development is just as important for the WWGSTL as research on academic development, while research into how youth learn 21st century skills is prioritized above learning sciences research into memorization or rote learning.

Many of the existing resources geared for a teacher audience focus primarily on cognitive research (e.g. Deans for Impact, 2015) or more narrowly on neuroscience research (e.g. Medina, 2011). Thus, we had to look elsewhere to locate research that is consistent with our views on learning, development, and schooling. Our search led us to the work of the Science of Learning and Development (SoLD) Initiative, a joint project of the American Institutes for Research, Center for Individual Opportunity, Education Counsel, Learning Policy Institute, Opportunity Institute, and Turnaround for Children that brought together a diverse group of science, practice, and policy leaders to synthesize research from the sciences of learning and development and to articulate implications of this research for practice and policy (SoLD Initiative, 2018).

The SoLD Initiative's work employs a relational developmental systems perspective that looks at the relations between individuals and contexts (Darling-Hammond et al., 2020). Relational developmental systems theories understand development as a process that occurs through an individual's actions and interactions within a lived physical and sociocultural world (Overton, 2015). A developmental systems perspective: 
makes it clear how children's development and learning are shaped by interactions among the environmental factors, relationships, and learning opportunities they experience, both in and out of school, along with physical, psychological, cognitive, social, and emotional processes that influence one another-both biologically and functionally-as they enable or undermine learning. (Darling-Hammond et al., 2020, p. 97).

This perspective, which foregrounds the complexity and variation inherent in development, is consistent with sociocultural theory. Moreover, the three research syntheses generated by the SoLD Initiative (Cantor et al., 2018; Darling-Hammond et al., 2020; Osher et al., 2018 are consistent with the WWGSTL's conception of the goals of schooling. These reviews synthesize literature far beyond the cognitive sciences, highlighting research findings that educational systems can use "to promote children's well-being, healthy development, and transferable learning" (Darling-Hammond et al., 2020, p. 97). With their attention to these additional aims of schooling, and their inclusion of scholarship from diverse scientific disciplines, we felt confident taking guidance from these scholars.

\section{Organizing the Research}

Alongside the question of what research to prioritize, we considered how to organize the research. We wanted to use a meaningful framework to organize SoLD concepts, in order to serve two main purposes. First, at the programmatic level, we wanted a tool for organizing research findings and making decisions about what to include in and exclude from the teacher education curriculum. Second, we wanted a framework that we could use consistently throughout coursework and fieldwork experiences to support teacher candidate knowledge development and transfer. An organizational structure can serve as a general schema, facilitating meaningful organization of new information and leading to deeper conceptual understanding (National Research Council, 2000). Schema also help learners to develop an abstract understanding of concrete research findings, supporting their ability to transfer that knowledge so that it is available for use in related future contexts (Engle et al., 2012). We believe that teacher candidates who learn about SoLD research findings in relation to a meaningful framework are more likely to understand the research deeply and use it adaptively in their future teaching.

The existing SoLD syntheses that are geared towards educators organize the research in varied ways, some more meaningful than others. For instance, some resources focus on a particular domain within the learning sciences, such as neuroscience, and summarize research findings that the authors have determined to be significant, without offering any organizational structure at all (e.g. Medina, 2011). The ABCs of How We Learn, a learning sciences text pitched as an introduction to core insights across the learning sciences, follows the format of an alphabet book, with one insight from the learning sciences for each letter of the alphabet ( $\mathrm{A}$ is for analogy, $\mathrm{B}$ is for belonging, etc.; Schwartz et al., 2016). While this 
structure is clever, it lacks meaning, and is thus unlikely to support teacher candidates in organizing SoLD concepts. Deans for Impact's report on the science of learning organizes cognitive principles under six overarching questions, including "How do students understand new ideas?" and "How do students learn and retain new information?" (2015). This structure does provide a meaningful framework, as it supports conceptual understanding as well as programmatic decision-making. However, because the framework is focused exclusively on principles of cognitive science, it is not well aligned with the WWGSTL's perspective of learning, development, and schooling. As we considered how to organize SoLD research findings in the WWGSTL program, we turned to Darling-Hammond, Flook, Cook-Harvey, Barron, and Osher's (2020) work with the SoLD Initiative as a starting point, due to its alignment with our perspective. Informed by developmental systems theory, Darling-Hammond et al. compiled a framework for synthesizing research on strategies that have been used in schools and classrooms to promote children's development, well-being, and learning (see Figure I). The "whole child" is at the center of the framework, literally and figuratively. Whereas traditional models of schooling "often compartmentalize... developmental processes as distinct from one another-and treat the child as distinct from the many contexts she experiences" (Darling-Hammond et al., 2020, p. 97), Darling-Hammond et al. argue for a more cohesive model. A whole child approach frames development as a multidimensional process that unfolds over time, as individuals develop academically, cognitively, ethically, physically, psychologically, socially, and emotionally. These multiple aspects of development are understood to be concurrent and interwoven, with both predictable milestones and individual variability. Individual and cultural differences in development are depicted as alternatives among many possible developmental pathways, as opposed to deficits (Bidell \& Fischer, 1992).

Drawing on the SoLD Initiative's recent syntheses of research on learning and development (Cantor et al., 2018; Osher et al., 2018), Darling-Hammond et al. (2020) suggest principles of practice for educators to support whole child development. Their framework specifies four domains: Supportive Environment, Productive Instructional Strategies, Social and Emotional Development, and System of Supports, which are depicted as quadrants of a circle that envelops the "whole child." The Supportive Environment quadrant refers to conditions that make a child feel safe and welcome in a learning context, including strong developmental relationships with adults and peers. Productive Instructional Strategies encompasses the pedagogical practices that help children develop deep understanding and reflect on their own learning. Social and Emotional Development includes the mindsets and skills that enable children to persist as confident, independent learners. Finally, the System of Supports quadrant refers to the multiple levels of support that exist within and beyond the school to meet the needs of all students, including those who are differently abled or who have experienced trauma. While each of these 


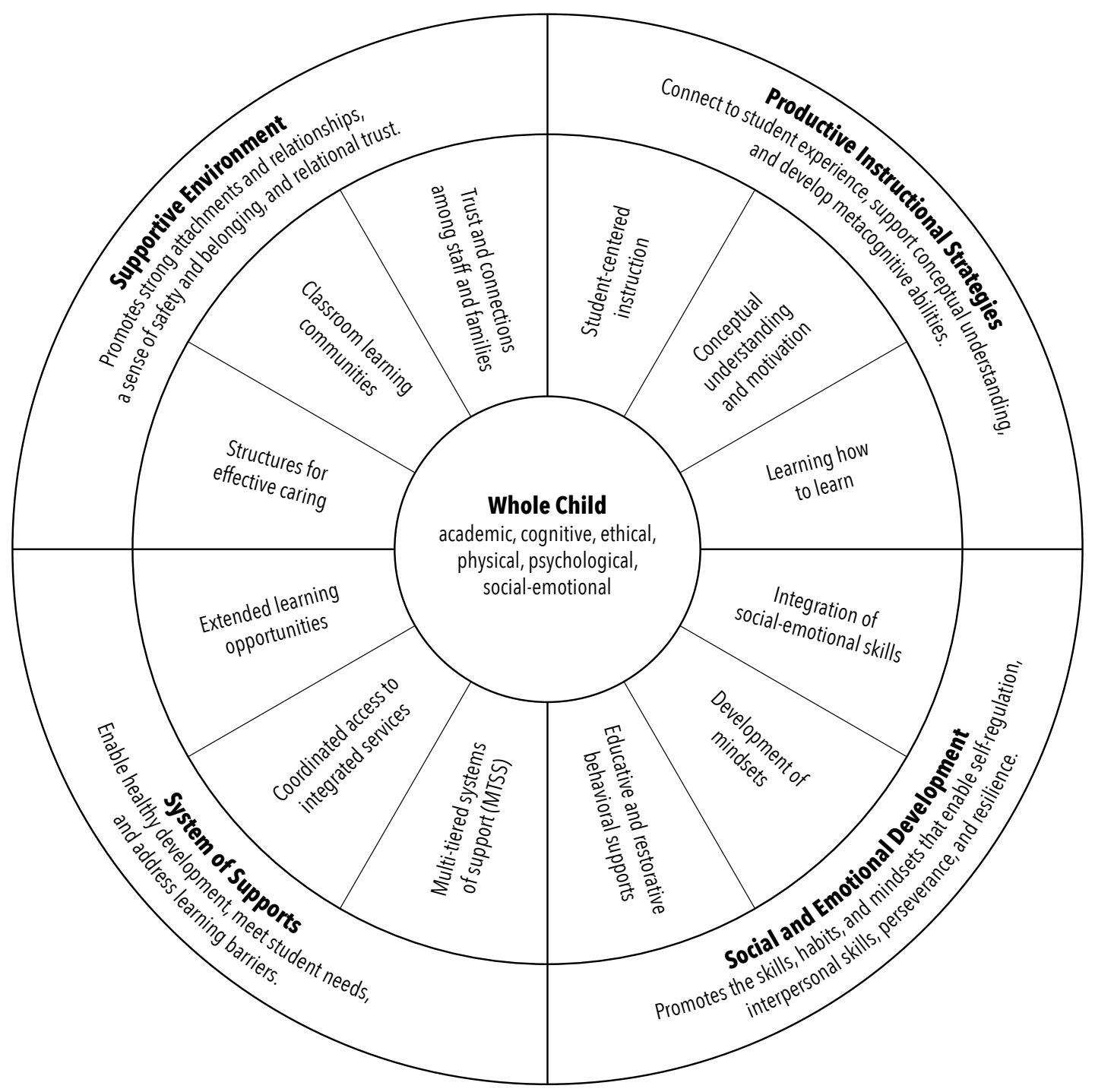

Figure 1. SoLD principles of practice. Reproduced from "Implications for educational practice of the science of learning and development" by L. Darling-Hammond, L. Flook, C., Cook-Harvey, B. Barron, \& D. Osher, 2020, Applied Developmental Science, 24(2), p. 98. Copyright 2019 Linda Darling-Hammond, Lisa Flook, Channa Cook-Harvey, Brigid Barron, and David Osher.

domains addresses unique elements of a given learning context, there is significant interaction between them, as well as overlap between the concepts housed within them.

Although Darling-Hammond et al. (2020) argue that children's learning and development are shaped by interactions between the environmental factors, relationships, and learning opportunities, both in and out of school, their framework foregrounds school and classroom contexts, rather 
than other social and cultural contexts. In a companion article, Osher, Cantor, Berg, Steyer, and Rose (2018) frame human development as occurring in nested ecological systems (Bronfenbrenner, 1994). This includes microsystems contexts, which are the child's immediate environment, such as families, schools, and neighborhoods, as well as macrosystems contexts, which are social and cultural values that are "operationalized through rituals, policies, protocols, routinized practices, and op-

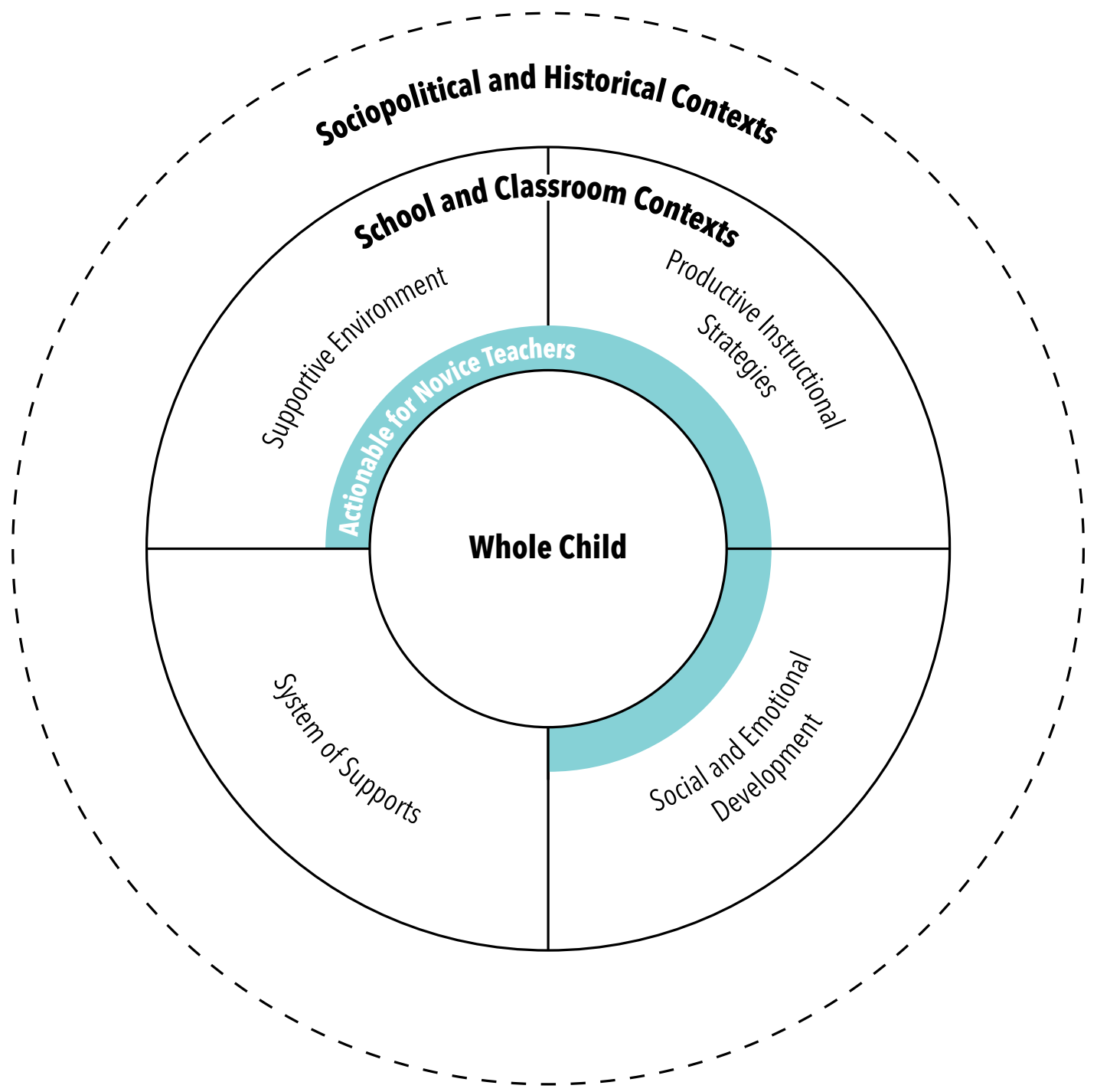

Figure 2 Expanded framework for guiding the incorporation of SoLD into teacher education.

Adapted with permission from "Implications for educational practice of the science of learning and development" by L. Darling-Hammond, L. Flook, C., Cook-Harvey, B. Barron, \& D. Osher, 2020, Applied Developmental Science, 24(2), Copyright 2019 Linda Darling-Hammond, Lisa Flook, Channa Cook-Harvey, Brigid Barron, and David Osher. 
portunity structures" (Osher et al., 2018, p. 15). Osher et al. emphasize the role of macrosystems factors like racism, poverty, and other conditions, noting the powerful impact that such factors have on children's more immediate contexts. Researchers have identified numerous ways that these factors influence children's experiences in schooling, through the teacher, the curriculum, and school policies. For instance, researchers have found that teachers' implicit biases about gender and race have negative effects on their expectations for students and on students' motivation and achievement (Chalabaev et al., 2009; Van Den Bergh et al., 2010). At the curriculum level, students of color and students from other marginalized groups are less likely to see themselves reflected in the curriculum, negatively impacting motivation and a sense of connection with school as an institution (Graham \& Taylor, 2002). At the school level, students of color are disproportionately impacted by policies that narrow school curriculum, by diverting time and other resources away from the arts, physical education, and deep learning activities towards instruction that directly prepares students for high-stakes testing (Au, 2007; Hamilton et al., 2007).

Osher at al.'s (2018) emphasis on the role of macrosystem factors in learning and development resonated with us, as the WWGSTL has a strong commitment to equity and justice. We have designated teaching for justice as a core competency, requiring that our graduates "interrogate the factors that contribute to inequities and take responsibility for fostering equity and justice for their students." Therefore, we decided to modify Darling-Hammond et al.'s framework to emphasize the role of sociopolitical and historical contexts. In our expanded framework for guiding the incorporation of SoLD into teacher education (see Figure 2), we followed Darling-Hammond et al. (2020) by placing the whole child in the center, surrounded by four domains of practice for educators. However, we added a larger concentric circle to visually accentuate the interaction of sociopolitical and historical contexts with learning and development (see Figure 2). This simple, spare framework emphasizes the interplay among these three, nested systems, rather than foregrounding one. It suggests that SoLD research must be understood and applied in context. The tasks of teaching, from setting goals for students' academic, social and emotional development, to establishing classroom norms, to planning and facilitating lessons, to collaborating with colleagues, occur within school and classroom contexts. However, all of these tasks impact and are impacted by both the individual children who comprise a class and the larger sociopolitical and historical contexts. As they seek to ground their classroom practice in SoLD, teachers should consider whether and how practices support the holistic development of each individual child. At the same time, teachers should be mindful of how sociopolitical and historical contexts shape their own biases, influence students' experiences, and inform curriculum and school policies. These inner and outer systems should serve as lenses through which to critically evaluate research on learning and development and reflect on implementation of this research. 
This framework serves to define the areas that will be included in the WWGSTL curriculum, informing the organization and selection of research, as well as the decisions about how to introduce this research to teacher candidates as described in the next section. In the longer term, we expect that it will serve as a tool that can support teacher candidates to develop and use deep, flexible knowledge of SoLD.

\section{Takeaways from Mapping the Territory}

- Identify priorities within the vast field of research on learning and development that correspond with the teacher education program's perspective on teaching, learning, and schooling.

- Develop or adopt a meaningful framework to organize SoLD concepts.

\section{Selecting SoLD Research}

Once we had decided what bodies of research on learning and development to prioritize and how to organize this research, we were ready to define a knowledge base for our teacher candidates. In this section, we illustrate how we used our expanded framework to guide decisions about which research findings from SoLD to include in the curriculum. We also describe other considerations in the selection process.

Our expanded framework for guiding the incorporation of SoLD into teacher education provided a structure for our review of SoLD research. We sought to identify research that teachers could use in their classroom practice related to the three quadrants in the "School and Classroom Contexts" section of the framework that are most within a teacher's locus of control: Supportive Environment, Productive Instructional Strategies, and Social and Emotional Development. We also considered what a teacher should know about the System of Supports domain to best promote their students' learning and development. The sociopolitical and historical contexts component of the framework served as a lens to critically examine SoLD research. We asked questions such as: Will an understanding of this concept encourage teachers to learn more about the sociopolitical and historical contexts surrounding schools?; How might an understanding of this concept allow teachers to disrupt or 
replace normative schooling practices and policies that negatively impact the most historically marginalized students?; Which students will benefit most from a teacher's understanding of this concept? The whole child component served as an additional lens, reminding us to look beyond frequently cited learning sciences research on cognitive development. We sought out additional research on social and emotional development, and on ways of promoting learning and development for varied learners.

We developed a list of major concepts from the SoLD research corresponding with the four quadrants in the School and Classroom Contexts section of the framework: Supportive Environment; Productive Instructional Strategies; Social and Emotional Development; and System of Supports. We began by surfacing concepts that were emphasized in influential learning sciences syntheses (Cantor et al., 2019; Darling-Hammond et al., 2020; Hammond, 2014; National Academies of Sciences, Engineering, and Medicine, 2018; National Research Council, 2000; Osher et al., 2018), and other resources that were already being used in the WWGSTL teacher education program. While there was significant consensus in the domains of Productive Instructional Strategies and Supportive Environment, the sources we consulted had less to say about the other two domains. Thus, we sought guidance from experts in these areas, who helped us to locate other resources, including several social and emotional learning frameworks. We ultimately decided to draw on the Building Blocks for Learning framework
(Stafford-Brizard, 2016) as a source of concepts related to Social and Emotional Development. This comprehensive student development framework, which is premised on the assumption that there are many possible pathways for development, is consistent with our perspective on development. We sought further feedback on the list from the entire graduate school faculty, as well as other colleagues with expertise in fields related to SoLD, including psychology, sociology, assessment, and learning design. With this feedback, we iteratively refined the list.

To finalize our list, we developed a set of inclusion criteria. We determined that concepts should fit the following three criteria:

1. Actionable: A novice secondary math or science teacher can apply this concept within their own classroom to improve student learning and development, even if there are influencing factors out of their control.

2. Fundamental: A novice secondary math or science teacher can apply their understanding of this concept frequently to support students' learning and development. Understanding and applying this concept is a prerequisite for advancing skill in teaching.

3. Research-backed: This concept has been found to be significant for student learning and development by multiple research studies. Studies may be quantitative, qualitative, or mixed methods, so long as they meet the standards for quality within that research paradigm.

Three of us independently reviewed the 
list using these criteria. We discussed discrepancies in our independent assessments, reached consensus, and removed any concepts that did not meet the criteria. Ultimately, we pared down the list to 19 concepts. The final list includes multiple concepts related to Supportive Environment, Productive Instructional Strategies, and Social and Emotional Development. There is only one concept under System of Supports, because we concluded that other concepts in this area did not meet the criterion of being actionable by a novice teacher.

We do not claim that the concepts on our list are objectively the most important concepts from SoLD, or would be the most important for any teacher education program. This list is influenced by the context of this particular teacher education program, which prepares secondary math and science teachers for careers in urban public schools. Furthermore, the emergent process that we followed, with its reliance on subject matter experts, is inherently subjective. If we had consulted with other experts, different concepts might have been added to the list. Despite these limitations, we are confident that understanding the concepts on the list, in relation to sociopolitical and historical contexts, as well as a whole child perspective, will enable novice teachers to more effectively support the learning and development of their students.

\section{Focal Concepts from SoLD}

Tables I-4 list the SoLD concepts that we selected for incorporation in the teacher education curriculum. The concepts are organized by the domain of the framework.
We briefly define each concept, explain its significance for learning and development, and offer implications for teachers.

\section{Takeaways from Selecting SoLD Desearch \\ - Use a framework to guide the selection of learning and development research to include in the teacher education curriculum. \\ - Use clear inclusion criteria to finalize the list of concepts. One important criterion is that the concepts selected must be actionable for a novice teacher.}


Table 1

\section{Focal Concepts from Supportive Environments}

Concept Definition \& Implications

Culturally sustaining pedagogy
For teaching to be considered culturally sustaining, it must support students' development of academic success, cultural competence, and sociopolitical consciousness (Ladson-Billings, 2014; Paris, 2012). Culturally sustaining pedagogy empowers students to experience individual achievement while challenging broader social inequalities. Teachers who practice culturally sustaining pedagogy are aware of how the values, traditions, communication styles, and so on held by students and their families interact with the way they learn, and are deliberate about incorporating content into their curriculum that affirms and sustains students' home cultures (Ladson-Billings, 2014; Paris \& Alim, 2017).
Designing learning environments
Learning environments include the norms, routines, and physical spaces that children experience in school. Environments promote learning when they: 1) feel safe and welcoming; 2) encourage engagement and focus; and 3) provide students with a sense of agency and ownership of the space and of their own learning. Teachers can involve students in the development of supportive learning environments by inviting them to participate in the co-construction of routines, cultures, and physical artifacts in the space (Freiberg \& Brophy, 1999; Jonassen \& Land, 2012).

Developmental relationships between young people and adults are "reciprocal, attuned, culturally responsive, and trustful" (Osher, Cantor, Berg, Steyer, \& Rose, 2018 , p. 8). Students who report strong developmental relationships with teachers are more likely to persist on challenging tasks and to feel comfortable taking risks and making mistakes as part of the learning process (Roehlkepartain et al., 2017). Teachers can cultivate developmental relationships by building in opportunities to get to know students as individuals and establishing themselves as trustworthy figures in their students' lives.

Teacher-caregiver interactions are effective when they make families feel welcome and heard as advocates for their children. Family engagement is one of the greatest predictors of students' academic success (Weiss et al., 2009). Practices for effective family engagement include offering proactive and positive home visits and phone calls, flexibly scheduling conferences to accommodate the needs of working parents, 
Concept Definition \& Implications

providing translated resources and/or interpreters for caregivers who do not speak English, and inviting caregivers to co-construct strategies and expectations for their children (Darling-Hammond et al., 2002; Jeynes, 2012).

Psychological safety

Psychological safety refers to the belief by participants in a learning community that the conditions are safe for interpersonal risk taking, enabling individuals to contribute without fear of judgement (Edmonson, 1999). In the classroom, psychological safety empowers students to ask questions and take intellectual risks, and cultivates an "identity safe" environment that honors their perspectives and responds to their needs (Steele \& Cohn-Vargas, 2013). Strategies for cultivating psychological safety include adopting culturally responsive teaching practices and creating low-stakes, non-graded learning opportunities where students can build knowledge through trial and error.

Trauma-informed pedagogy
Trauma-informed teaching strategies prioritize safety, a sense of connection, and the effective management of impulses and emotions (Bath, 2008). These practices are meant to support the physical, emotional, and cognitive well-being of students who have experienced adversity and toxic stress, which can impede brain development and interfere with students' ability to succeed in school (Crosby, 2015; Shonkoff et al., 2012). Examples of trauma-informed practices include building strong developmental teacher-student relationships, using consistent and predictable classroom routines, and offering flexible opportunities for assessment to reduce stress and help nurture students' academic mindsets (Brunzell et al., 2016).

Table 2

\section{Focall Concepts from Productive Instructional Strategies}

Concept

Cognitive load
Definition \& Implications

Cognitive load is the extent to which an individual's various working memory resources are being taxed in a particular learning scenario (Sweller, 1988). Intrinsic load (complexity that is inherent in the content or task) and germane load (work that facilitates knowledge construction) are productive for learning, while extraneous load (tasks or information that distract from the main learning goals) should be minimized (Paas et al., 2003). Teachers can help students manage cognitive load by reducing 
Concept Definition \& Implications

unnecessary information or embellishments in their curricular materials, as well as by offering tools like scratch paper, graphic organizers, and glossaries that enable students to focus their attention on the most important content or tasks.

Curiosity

Curiosity is a source of intrinsic motivation characterized by an interest in surprising, novel, or complex stimuli or experiences (Loewenstein, 1994; Silvia, 2018). Fostering curiosity makes the brain more receptive to learning, is associated with increased academic performance, and supports the disciplinary habits of inquiry that are critical to science and mathematics learning (Rutherford \& Ahlgren, 1991; Von Stumm et al., 2011). Strategies for nurturing curiosity include introducing new concepts with a provocation or a phenomenon that violates students' expectations, as well as incorporating self-directed learning opportunities that invite students to ask and pursue their own questions.

Expertise

Expertise refers to advanced knowledge within a domain. Instruction designed to promote expertise enables students to go beyond procedural knowledge to develop deep conceptual and structural understandings (National Research Council, 2000). Teachers can support the development of expertise by encouraging students to pursue increasingly challenging tasks that build knowledge rather than defaulting to routinized strategies (Bereiter \& Scardamalia, 1993).

Feedback

Feedback is information provided about one's learning, either during or following instruction (Hattie \& Timperley, 2007). Students need timely, effective feedback in order to advance their understanding and improve performance. Feedback from teachers is most effective when it is specific, explicitly connected to learning goals, accompanied by recommendations and tools for improvement, and followed by opportunities for revision so that students can apply the feedback they have received (Hattie \& Gan, 2011).

Metacognition

Metacognition, or the process of thinking about our own thinking, enables us to assess the status of our understanding and make decisions accordingly (Flavell, 1979). All students benefit from explicit instruction on practices to help them effectively monitor and regulate their own learning, though research suggests that the teaching of metacognition has the greatest impact on typically low-achieving students (Zohar \& David, 2008). One way to promote metacognition is through the use of learning 
Concept Definition \& Implications

journals, where students are asked to reflect on content they find challenging, study habits that have worked for them, how their thinking has changed over the course of a unit, and so on.

Role of prior knowledge/ Students bring pre-existing understandings and beliefs to any learning context. experiences Acknowledging where students are starting from is a critical step in building knowledge, cultivating engagement, and encouraging transfer (National Research Council, 2000). Starting a new lesson or unit with an exercise that asks students to reflect on what they already know or believe about the content being introduced is a useful way to activate students' existing knowledge and surface any misconceptions that might inform how to proceed with instruction (Driver, 1988).

Transfer

Transfer is the process of applying one's understanding to prior or future contexts. Pedagogical moves that support transfer are necessary so that students are sensitive to occasions to apply their understanding, capable of making those connections, and sufficiently motivated to do so (Perkins et al., 1993). Teachers can promote transfer by expansively framing content to highlight how it relates to other times, places, or people outside the initial learning context (Engle et al., 2012).

Table 3

\section{Focal Concepts from Social \& Emotionall Development}

\section{Concept Definitions \& Implications}

Agency Agency refers to an individual's capacity for autonomous decision-making and behavior (Ryan \& Deci, 2002; Toshalis \& Nakkula, 2012). Students show increased motivation and engagement when they are empowered to make choices about their own learning and participate as active contributors to their learning community (Deci et al., 1991). Teachers can support the development of agency by inviting students to co-construct their own learning goals as well as a plan for how to meet them.

Growth mindset
Growth mindset refers to the belief that one's ability and performance can improve through effort (Dweck, 1999; Yeager \& Walton, 2011). Students who hold a growth mindset are more likely to be self-motivated and to persevere in the face of challeng- 
es. Teachers can support the development of a growth mindset by using language that emphasizes persistence over performance, affirming evidence of student progress, and designing assessments that allow for revision and continued effort.

Relevance of school Relevance of school refers to a perception that the content being studied holds value, such that the student finds it intrinsically interesting or important, and/or believes that it will be useful for future endeavors (Brophy, 2008; Wigfield and Eccles, 1992). Students are more likely to engage, persist, and to take on more challenging tasks when they believe the work is relevant. Teachers can help students find relevance by using real world examples, explaining connections between and applications for the content being taught, and providing opportunities for students to pursue individual interests and goals.

Self-efficacy

Self-efficacy is the belief that one is capable of doing something successfully (Bandura, 1997; Ryan \& Deci, 2002). Students who believe they can be successful are more likely to persist longer, work harder, and take risks (Eccles \& Roeser, 2009). Teachers can support the development of self-efficacy by regularly affirming student competence and by providing multiple opportunities to revise work and demonstrate mastery.

Sense of belonging

Sense of belonging refers to a student's perception that they are welcome members of a learning community in which they can be their authentic selves (Baumeister \& Leary, 1995; Kumar et al., 2018). Students who feel that they belong in their academic community demonstrate more positive attitudes toward school, a deeper investment in their learning, and a stronger sense of their own identity (Osterman, 2000). Ways of cultivating a sense of belonging include demonstrating personal knowledge of students, inviting a variety of modes of participation, and choosing curriculum that represents and affirms the diverse cultural practices and worldviews of students in the classroom. 
Table 4

\section{Focall Concepts from System of Supports}

\section{Concept Definition \& Implications}

Multi-tiered system of supports
The Every Student Succeeds Act (ESSA, 2015) defines a multi-tiered system of support as "a comprehensive continuum of evidence-based, systemic practices to support a rapid response to students' needs, with regular observation to facilitate data-based instructional decision making." The tiers are designed to serve students by providing support structures that increase in intensity (Massachusetts Department of Elementary and Secondary Education, 2018), moving from universal support that occurs in the classroom (Tier 1) to more targeted and intensive support involving outside services like tutoring, counseling, and family outreach (Tiers 2 and 3). Teachers should work to incorporate practices at the Tier 1 level, such as culturally responsive pedagogy and universal design for learning, and should know how to help their students access resources beyond Tier 1 .

\section{Integrating SoLD into the Curriculum}

In order to support teachers in developing a deep understanding of SoLD and its classroom implications, we envision integrating SoLD research throughout the teacher preparation program. In this section, we paint a picture of what this might look like. We subsequently discuss the steps taken so far at the WWGSTL towards realizing that vision, as well as those that we intend to take in the future. We conclude with lessons learned.

We envision integrating SoLD research findings into every module in the teacher preparation program. ${ }^{1}$ We plan to have teacher candidates engage directly with the research, as well as with resources that focus on the pedagogical implications of this research. Teacher candidates will be guided to consider SoLD resources in relation to the larger SoLD framework, making connections between concepts in different domains of the framework, and considering the larger sociopolitical and historical contexts. In particular, we will encourage teacher candidates to evaluate resources in light of the contexts in and surrounding the schools where they do their fieldwork. We will also ask teacher candidates to thoughtfully select and implement research-backed strategies and critically reflect on their practice. At every stage of the program, teacher candidates will have opportunities to put SoLD research into practice adap-

I The WWGSTL uses challenge-based modules, rather than courses. 
tively, in response to the specific needs of their students as well as classroom, school, sociopolitical, and historical contexts.

We envision teacher candidates consolidating their understanding of SoLD as they engage in intentionally designed learning experiences over the course of the program. As teacher candidates proceed through the program, we plan to provide multiple opportunities to revisit the same concepts, in order to explore their application in different contexts. For instance, teacher candidates might initially explore the concept of cognitive load when learning how to design lessons, and subsequently revisit that concept to consider its application specifically to English language learners or students with disabilities. We expect that consistent use of the same framework throughout coursework and fieldwork will help teacher candidates to make connections between concepts. We anticipate supporting these connections through learning experiences, such as concept mapping exercises, where teacher candidates individually or collectively create maps that illustrate the relationships among the concepts they are learning about. Opportunities for revision can also support teacher candidates in consolidating their knowledge. Teacher candidates might iterate on assignments or artifacts of practice from early in the program, based on their developing knowledge or student learning and development.

We envision a program-wide assessment approach that will evaluate not just teacher candidates' use of research-backed strategies, but also their understanding of the research itself and of the larger SoLD framework. Use of the strategies alone is not sufficient, because, as we argued above, teachers need to understand the research in order to use it adaptively to support students' learning and development as contexts and circumstances change. Thus, teacher candidates would be expected to articulate a rationale for their pedagogical choices, connecting their practice to research and theory.

\section{First Steps towards Curriculum Integration}

We began the work of integrating SoLD into the WWGSTL's curriculum with a small-scale pilot during the 2019-2020 academic year. We revised four of the eleven curriculum modules to incorporate SoLD concepts. We selected modules that were clearly related to three of the quadrants within the framework: 1) Productive Instructional Strategies; 2) Social and Emotional Development; and 3) Supportive Environments. In this section, we briefly describe our pilot program and sketch the changes needed to realize the vision described above.

For 2019-2020, we revised the module on lesson and unit design to integrate SoLD research from the productive instructional strategies domain on cognitive load, transfer, and expertise. Teacher candidates individually explored a variety of text and video resources that presented SoLD concepts along with their implications for teachers, and discussed ideas from these resources with their peers and faculty members. For their final assessment, teacher candidates submitted a lesson design along with a 
reflection on questions, including:

- How does your lesson plan leverage instructional strategies from the learning sciences?

- What strategies are present in your lesson?

- Why did you decide to use these strategies for this lesson?

- Why are they appropriate for the learning objective(s) and the needs of the students in the class?

Through this assignment, teacher candidates demonstrated their understanding of learning sciences research as well as their ability to apply it in their lesson designs.

Similarly, we revised a module on classroom culture to incorporate research from the supportive environments and social and emotional development domains of the framework. Teachers candidates explored research on and discussed the classroom implications of concepts including belonging, developmental relationships, and culturally responsive teaching. They sought to put the research into practice through an assessment task in which they developed a plan for setting and implementing classrooms norms. Alongside their plans, teacher candidates submitted a rationale that addressed questions, including:

- How is your norm-setting plan supported by established research and theory?

- How will your example norms promote safety, belonging, and relational trust for your students?

- How well are the norms supported by established research and theory?

- Make sure that your reasoning is not grounded in only your personal preference or opinion.

These early prototypes illustrate a deliberate approach to integrating SoLD research into the curriculum. Through both modules, teacher candidates had opportunities to explore research findings, consider their classroom implications, apply them to their own classroom plans, and articulate the connection between research and practice. With these prototypes as an example of curriculum module-level integration, we are now tackling the more extensive task of program-wide integration.

\section{A Process for Program-Wide Integration}

In this section, we detail the ongoing work that we are doing to integrate SoLD into the curriculum at the WWGSTL. After deciding on a knowledge base, as described above, the next step was to analyze the teacher education program's existing curriculum to identify where SoLD concepts were already included as well as opportunities to include other concepts. We developed a detailed proposal for where to include each of the selected SoLD concepts in the teacher education curriculum, and we sought feedback on the proposal from the complete faculty. Feedback included suggestions at the curriculum module-level as well as program-level feedback on the sequence of concepts. We iteratively refined the plan to improve the sequence and to increase alignment between SoLD con- 
tent and other content in the curriculum modules.

We also undertook the task of creating resources that can be used in designing and/or revising course content. We created two types of resources: 1 ) an encyclopedia of all the SoLD concepts included in the curriculum; and 2) a SoLD overview for each curriculum module. The encyclopedia includes an entry for each concept, consisting of a definition and discussion of implications for teachers, along with an annotated list of hyper-linked resources. We made sure to include a range of resources, such as research briefs, articles written for teachers, and short videos illustrating teaching strategies consistent with the research. An example is included as Appendix A. The encyclopedia is designed to support faculty and learning designers in learning more about the research in order to teach it to teacher candidates. It can also be accessed independently by teacher candidates to learn more about or to review the research. Additionally, we developed a SoLD overview for each curriculum module that highlights the relationships between the SoLD research included in that module and other content, connects the included research concepts to the framework, and highlights featured teaching strategies, based on the research. Appendix B includes an example overview from "Making Big Ideas Real" which is the curriculum module on lesson and unit design. We shared prototypes of these materials with faculty and learning designers, and incorporated their feedback, to ensure their usability.

In addition to supporting integration at the curriculum module level, we are also considering program-wide issues. Our future work includes:

- Developing an introduction to the expanded framework for guiding the incorporation of SoLD into teacher education;

- Designing learning experiences to support teacher candidates in consolidating their developing understanding of SoLD, both within and outside of courses;

- Collaborating with the WWGSTL's Assessment Director to develop assessments;

- Collaborating with the WWGSTL's Director of Clinical Learning to plan how to integrate SoLD into teacher candidates' fieldwork.

Thoughtful engagement with these projects makes it more likely that teacher candidates will be able to make use of the SoLD research that they learn about in their courses, in their fieldwork, and well beyond, into their work as teachers. 
Takeanays from Integrating SoLD into the Curriculum

- Develop a detailed proposal for integrating SoLD concepts across the teacher education curriculum. Seek and incorporate feedback from the faculty.

- Develop and compile resources on the research as well as implications for practice that can be used to design and/or revise course content. Resources should be educative for faculty as well as for teacher candidates.

- Provide multiple opportunities for teacher candidates to consolidate their understanding of SoLD.

- Collaborate with clinical faculty on a coordinated approach to integrating SoLD into teacher candidates' fieldwork.

- Use an assessment approach that evaluates teacher candidates understanding of the research on learning and development, their use of research-based strategies, and their ability to evaluate SoLD-based strategies in relation to the learners in the classroom and larger sociopolitical and historical contexts.

\section{Getting SoLD into the Classroom}

In the pages above, we shared our vision of a teacher preparation program grounded in SoLD, and we detailed our process for bringing about program-wide integration. We also pulled out our takeaways, which we anticipate will be helpful to other teacher education programs.

We believe that this work has the potential to bring SoLD to where it matters mostschools. We hope to foster the development of a new generation of teachers, who reject outdated, and often damaging, practices and beliefs, such as instructionist modes of teaching (Sawyer, 2014), coercive discipline practices (Darling-Hammond, et al., 2020), deficit views of children from specific identity groups (Hammond, 2014), and linear models of development (Bidell \& Fischer, 1992). As teacher candidates delve into the research on learning and development, we posit that they will instead embrace the need to foster the holistic development of every student, through creating supportive learning environments, implementing productive instructional strategies, tapping into a system of supports, and vigilantly attending to the influence of sociopolitical and historical contexts. Teachers who have engaged with SoLD research throughout their pre-service education, and examined that research through the lens of sociopolitical and historical contexts, will enter 
their classrooms better equipped for the challenges ahead.

Too often teachers are treated as technicians and expected to faithfully implement teaching strategies, curriculum, and discipline policies that are handed down from above (Zeichner, 2017). However, teaching well requires intellectual, not technical, work (Giroux, 1985; Mascio, 2016). Arming new teachers with a deep and flexible knowledge of SoLD will allow them to act as professionals, using their adaptive expertise to exercise discretion and judgment. Rather than unquestioningly implementing curriculum and policies, they can draw on their understanding of the research and of their students to critically evaluate these mandates, and to modify, reinterpret, or even subvert them, in the best interests of their students. Teachers who have engaged with this research throughout their pre-service education can draw upon this knowledge as fodder for the intellectual work of designing and modifying learning environments and instructional plans to support the learning and development of all their students.

\section{References}

Adelman, H. S., \& Taylor, L. (2008). Schoolwide approaches to addressing barriers to learning and teaching. In B. Doll \& J. Cummings (Eds.), Transforming school mental health services: Population-based approaches to promoting the competency and wellness of children. Thousand Oaks, CA: Corwin Press.

$\mathrm{Au}, \mathrm{W}$. (2007). High-stakes testing and curricular control: A qualitative metasynthesis. Educational Researcher, 36(5), 258-267.

Barnett, S. M., \& Ceci, S. J. (2002). When and where do we apply what we learn?: A taxonomy for far transfer. Psychological Bulletin, 128(4), 612-637.

Bartolomé, L. I. (2004). Critical pedagogy and teacher education: Radicalizing prospective teachers. Teacher education quarterly, 3I(I), 97-122.

Bath, H. (2008). The three pillars of trauma-informed care. Reclaiming children and youth, 17(3), 17-21.

Baumeister, R. F., \& Leary, M. R. (1995). The need to belong: desire for interpersonal attachments as a fundamental human motivation. Psychological bulletin, 117(3), 497.

Bereiter, C., \& Scardamalia, M. (1993). Surpassing ourselves: An inquiry into the nature and implications of expertise. Chicago, IL: Open Court.

Bidell, T. R., \& Fischer, K. W. (1992). Beyond the stage debate: Action, structure, and variability in Piagetian theory and research. In C. A. Berg \& R. J. Sternberg (Eds.), Intellectual development (pp. 100-140). New York, NY: Cambridge University Press. 
Brunzell, T., Stokes, H., \& Waters, L. (2016). Trauma-informed positive education: Using positive psychology to strengthen vulnerable students. Contemporary School Psychology, 20(I), 63-83.

Bryk, A., \& Schneider, B. (2002). Trust in schools: A core resource for improvement. New York: Russell Sage Foundation.

Cantor, P., Osher, D., Berg, J., Steyer, L., \& Rose, T. (2019). Malleability, plasticity, and individuality: How children learn and develop in context. Applied Developmental Science, 23(4), 307-337.

Cochran-Smith, M. and Lytle, S. L. (1999). Relationships of knowledge and practice: Teacher learning in communities. Review of Research in Education, 24(I) 249-305.

Crosby, S. D. (2015). An ecological perspective on emerging trauma-informed teaching practices. Children \& Schools, 37(4), 223-230.

Darling-Hammond, L., Ancess, J., \& Ort, S. W. (2002). Reinventing high school: Outcomes of the coalition campus schools project. American Educational Research Journal, 39(3), 639-673.

Darling-Hammond, L., Flook, L., Cook-Harvey, C., Barron, B., \& Osher, D. (2020). Implications for educational practice of the science of learning and development. Applied Developmental Science, 24(2), 97-140.

Darling-Hammond, L., Oakes, J., Wojcikiewicz, S., Hyler, M. E., Guha, R., \& Podolsky, A. (2019). Preparing teachers for deeper learning. Cambridge, MA: Harvard Education Press.
Deci, E. L., Vallerand, R. J., Pelletier, L. G., \& Ryan, R. M. (1991). Motivation and education: The self-determination perspective. Educational psychologist, 26(3-4), 325-346.

Deans for Impact (2015). The science of learning. Austin, TX. Retrieved from https://deansforimpact.org/wp-content/ uploads/2016/12/The_Science_of_Learning. pdf.

Deans for Impact (2020). Learning by scientific design: Early insights from a network transforming teacher preparation. Retrieved from https://deansforimpact.org/ wp-content/uploads/2020/o3/Deans_for_ Impact_LbSD_Report_FINAL-I.pdf Driver, R. (1988). Changing conceptions. Journal of Research in Education, 6(3), 161-198.

Eccles, J.S., Adler, T.F., Futterman, R., Goff, S.B., Kaczala, C.M., Meece, J.L., and Midgley, C. (1983). Expectancies, values, and academic behaviors. In J.T. Spence (Ed.), Achievement and achievement motivation (pp. 75-146). San Francisco: W.H. Freeman.

Eccles, J. S., \& Roeser, R. W. (2009). Schools, academic motivation, and stage-environment fit. In R. M. Lerner \& L. Steinberg (Eds.), Handbook of adolescent psychology: Individual bases of adolescent development (p. 404-434). New York, NY: John Wiley \& Sons Inc. https://doi. org/10.1002/9780470479193.adlpsyоо1о13

Edmondson, A. (1999). Psychological safety and learning behavior in work teams. Administrative science quarterly, 44(2), 350-383.

Engle, R. A., Lam, D. P., Meyer, X. S., \& Nix, S.E. (2012). How does expansive framing 
promote transfer? Several proposed explanations and a research agenda for investigating them. Educational Psychologist, 47(3), 215-231.

Esmonde, I., \& Booker, A. N. (Eds.). (2016). Power and privilege in the learning sciences: Critical and sociocultural theories of learning. New York, NY: Taylor \& Francis.

ESSA (2015). Every student succeeds act of 2015, Pub. L. No. 114-95 114 Stat. 1177 (2015-2016).

Fischer, K. W., Yan, Z., \& Stewart, J. (2003). Adult cognitive development: Dynamics in the developmental web. In J. Valsiner, \& K. Connolly (Eds.), Handbook of developmental psychology (pp. 491-516). Thousand Oaks, CA: Sage.

Flavell, J. H. (1979). Metacognition and cognitive monitoring: A new area of cognitive-developmental inquiry. American psychologist, 34(10), 906-911.

Freiberg, H. J., \& Brophy, J. E. (1999). Beyond behaviorism: Changing the classroom management paradigm. Boston, MA: Allyn and Bacon.

Giroux, H. A. (1985). Intellectual labor and pedagogical work: Rethinking the role of teacher as intellectual. Phenomenology + Pedagogy, 20-32

Gordon, R., Kane, T. J., \& Staiger, D. O. (2006). Identifying effective teachers using performance on the job. (The Hamilton Project Policy Brief No. 2006-oI). Brookings Institution.

Hattie, J., \& Gan, M. (2011). Instruction based on feedback. In R. E. Mayer \& P. A. Alexander (Eds.), Handbook of research on learning and instruction (pp. 249-271). New York, NY: Routledge.

Hattie, J., \& Timperley, H. (2007). The power of feedback. Review of educational research, 77(I), 81-112.

Hamilton, L. S., Stecher, B. M., Marsh, J. A., McCombs, J. S., Robyn, A., Russell, J. L., et al. (2007). Standards-based accountability under No Child Left Behind: Experiences of teachers and administrators in three states. Santa Monica, CA: RAND.

Hammond, Z. (2014). Culturally responsive teaching and the brain: Promoting authentic engagement and rigor among culturally and linguistically diverse students. Thousand Oaks, CA: Corwin Press.

Hanushek, E. A., \& Rivkin, S. G. (2012). The distribution of teacher quality and implications for policy. Annual Review of Economics, 4(I), 131-157.

Hargreaves, A., \& Goodson, I. (2006). Educational change over time? The sustainability and nonsustainability of three decades of secondary school change and continuity. Educational Administration Quarterly, 42(I), 3-4I.

Jeynes, W. (2012). A meta-analysis of the efficacy of different types of parental involvement programs for urban students. Urban education, 47(4), 706-742.

Jonassen, D., \& Land, S. (Eds.). (2012). Theoretical foundations of learning environments. London, UK: Routledge.

Kumar, R., Zusho, A., \& Bondie, R. (2018). Weaving cultural relevance and achievement motivation into inclusive classroom 
cultures. Educational Psychologist, 53, 78-96.

Ladson-Billings, G. (2014). Culturally relevant pedagogy 2.0: aka the remix. Harvard Educational Review, 84(I), 74-84.

Lave, J. (1996). Teaching, as learning, in practice. Mind, culture, and activity, 3(3), 149-164.

Lee, C. D. (2010). Soaring above the clouds, delving the ocean's depths: Understanding the ecologies of human learning and the challenge for education science. Educational Researcher, 39(9), 643-655.

Lee, C. (2016) Critical learning opportunities for the learning sciences. In I. Esmonde \& A. N. Booker (Eds.). Power and privilege in the learning sciences: Critical and sociocultural theories of learning (pp. vii-xii). New York, NY: Taylor \& Francis

Lee, V. (2017). A Short History of the Learning Sciences. In R. E. West (Ed.) Foundations of learning and instructional design technology. Retrieved from https:// lidtfoundations.pressbooks.com/chapter/ learning-sciences-by-victor-lee/

Loewenstein, G. (1994). The psychology of curiosity: A review and reinterpretation. Psychological Bulletin, 116(I), 75-98.

Mascio, B. (2016). True teaching expertise: The weaving together of theory and practice. American Educator, 40(2), 18-21.

Massachusetts Department of Elementary and Secondary Education (2018). Multitiered system of support: A blueprint for Massachusetts educators. Retrieved from https://matoolsforschools.com/resources/ mtss-blueprint
Medina, J. (2011). Brain rules: 12 principles for surviving and thriving at work, home, and school. Seattle, WA: Pear Press.

National Academies of Sciences, Engineering, and Medicine. (2018). How people learn II: Learners, contexts, and cultures. Washington, DC: The National Academies Press. https://doi.org/10.17226/24783.

National Research Council. (2000). How people learn: Brain, mind, experience, and school: Expanded Edition. Washington, DC: The National Academies Press. https://doi. org/10.17226/9853.

Osher, D., Cantor, P., Berg, J., Steyer, L., \& Rose, T. (2018). Drivers of human development: How relationships and context shape learning and development. Applied Developmental Science, 24(I), 6-36.

Osterman, K.F. (2000). Students' need for belonging in the school community. Review of Educational Research, 70(3), 323-367

Overton, W. F. (2015). Processes, relations and relational-developmental-systems. In W. F. Overton, \& P. C. M. Molenaar (Eds.), Handbook of child psychology and developmental science: Vol. 1. Theory and method (7th ed., pp. 9-62). Hoboken, NJ: Wiley.

Paas, F., Renkl, A., \& Sweller, J. (2003). Cognitive load theory: Instructional implications of the interaction between information structures and cognitive architecture. Instructional Science, 32(I/2), I-8.

Paris, D. (2012). Culturally sustaining pedagogy: A needed change in stance, terminology, and practice. Educational Researcher, 4I(3), 93-97.

Paris, D. (2016). On educating culturally 
sustaining teachers. Teaching Works Working Papers. Retrieved from http://www. teachingworks.org/images/files/TeachingWorks_Paris.pdf

Paris, D., \& Alim, H. S. (Eds.). (2017). Culturally sustaining pedagogies: Teaching and learning for justice in a changing world. New York, NY: Teachers College Press.

Perkins, D. N., Jay, E., \& Tishman, S. (1993). Beyond abilities: A dispositional theory of thinking. Merrill-Palmer Quarterly (1982-), I-21.

Podolsky, A., Kini, T., Bishop, J., \& Darling-Hammond, L. (2016). Solving the teacher shortage: How to attract and retain excellent educators. Palo Alto, CA: Learning Policy Institute.

Roehlkepartain, E. C., Pekel, K., Syvertsen, A. K., Sethi, J., Sullivan, T. K., \& Scales, P. C. (2017). Relationships first: Creating connections that help young people thrive. Minneapolis, MN: Search Institute, 1-20.

Rosebery, A. S., Warren, B., \& Lee, C. D. (2014). Learning as a cultural process: Achieving equity through diversity. In R. K. Sawyer (Ed.) The Cambridge handbook of the learning sciences, (2nd ed., pp. 686706). New York, NY: Cambridge University Press.

Rutherford, F. J., \& Ahlgren, A. (1991). Science for all Americans. Oxford, UK: Oxford University Press.

Ryan, R. M., \& Deci, E. L. (2002). An overview of self-determination theory: An organismic-dialectical perspective. In E.

L. Deci \& R. M. Ryan (Eds.), Handbook of self-determination research (pp. 3-33).
Rochester, NY: University of Rochester Press.

Sawyer, R. K. (Ed.). (2014). The Cambridge handbook of the learning sciences, 2nd Ed.. Cambridge University Press.

Schonert-Reichl, K. A., Hanson-Peterson, J. L., \& Hymel, S. (2015). SEL and preservice teacher education. In J. A. Durlak, C. E. Domitrovich, \& R. P. Weissberg (Eds.) Handbook of social and emotional learning: Research and practice (pp. 406-421). New York, NY: Guilford Press.

Schwartz, D. L., Tsang, J. M., \& Blair, K. P. (2016). The ABCs of how we learn: 26 scientifically proven approaches, how they work, and when to use them. New York, NY: WW Norton \& Company.

Science of Learning \& Development Initiative (2018). Science of Learning \& Development (SoLD) Initiative Executive Summary. Retrieved from https://drive.google.com/file/d/1w_juzRcJYbxFXpib7DBCXofniAnI8VvB/ view

Shonkoff, J. P., Garner, A. S., Siegel, B. S., Dobbins, M. I., Earls, M. F., McGuinn, L., et al. (2012). The lifelong effects of early childhood adversity and toxic stress. Pediatrics, 129(I), e232-e246.

Silvia, P. J. (2018). Curiosity and motivation. In R. M. Ryan (Ed.), Oxford handbook of motivation. New York, NY: Oxford University Press.

Stafford-Brizard, K. B. (2016). Building blocks for learning: A framework for comprehensive student development. Turnaround for Children. Retrieved from https://www.turnaroundusa.org/wp-con- 
tent/uploads/2016/o3/Turnaround-forChildren-Building-Blocks-for-Learningx-2. pdf

Steele, D. M., \& Cohn-Vargas, B. (2013). Identity safe classrooms: Places to belong and learn. London, UK: Corwin Press

Sweller, J. (1988). Cognitive load during problem solving: Effects on learning. Cognitive Science, 12(20), 257-285.

Toshalis, E., \& Nakkula, M. J. (2012). Motivation, engagement, and student voice. Boston, MA: Jobs for the Future.

Weiss, H., Bouffard, S., Bridglall B., \& Gordon, E. (2009). Reframing family involvement in education: Supporting families to support educational equity. New York, NY: Campaign for Educational Equity, Teachers College, Columbia University. http://eric. ed.gov/?id= ED523994

Von Stumm, S., Hell, B., \& Chamorro-Premuzic, T. (2011). The hungry mind: Intellectual curiosity is the third pillar of academic performance. Perspectives on Psychological Science, 6(6), 574-588.

Wenger, E. (2000). Communities of practice and social learning systems. Organization, 7(2), 225-246. https://doi. org/10.1177/135050840072002

Wertsch, J. V., Del Rio, P., \& Alvarez, A. E. (1995). Sociocultural studies of mind. Cambridge, England: Cambridge University Press.

Wigfield, A., and Eccles, J.S. (1992) The development of achievement task values: A theoretical analysis. Developmental Review, 12, 265-310.

Yeager, D.S., and Walton, G.M. (2011)
Social-psychological interventions in education: They're not magic. Review of Educational Research, 81 (2), 267-301.

Zeichner, K. M. (2017). The struggle for the soul of teacher education. New York, NY: Routledge.

Zohar, A., \& David, A. B. (2008). Explicit teaching of meta-strategic knowledge in authentic classroom situations. Metacognition and Learning, 3(I), 59-82. 


\section{Appendix A}

\section{Expertise}

\section{Framework Quadirant:}

Productive Instructional Strategies

\section{Definition:}

Expertise refers to advanced knowledge within a domain. Instruction designed to promote expertise enables students to go beyond procedural knowledge to develop deep conceptual and structural understandings (National Research Council, 200o). Teachers can support the development of expertise by encouraging students to pursue increasingly challenging tasks that build knowledge rather than defaulting to routinized strategies (Bereiter \& Scardamalia, 1993).

\section{Challenges Where Concept is Addressed:}

- $\quad$ Making Big Ideas Real (MBIR); featured

- Assessment; reviewed, with challenge-specific resources

\section{Relevant Strategies:}

- When possible, offer opportunities for authentic assessment. Much like we wouldn't grant someone a lifeguard certification or driver's license without putting them in the pool or behind the wheel, it is important to consider the contexts in which you hope students will apply their understanding, and work to design assessments that closely approximate those contexts. Project-based and problem-based learning approaches are often useful for generating authentic assessment opportunities. [Assessment]

- Introduce the same information multiple times in varied contexts. This encourages transfer by preventing knowledge from becoming bound to a single domain, and has the potential to engage students who may have greater interest or a stronger skill set in one context versus another. [MBIR]

- Incorporate opportunities for "productive uncertainty." Encountering puzzles or areas of disagreement can motivate students to engage in the disciplinary practices of argumentation and explanation. To prevent students from feeling overwhelmed or discouraged, keep the aspects of uncertainty bounded in scope -- for instance, ask students to evaluate and decide between several alternative methods for data analysis. [MBIR] 


\section{Appendix A (continued)}

\section{Related Resources}

Resource

Description

Challenge Alignment

Knowledge and Practice: The Real

Keys to Critical Thinking

Article by educational researcher Daniel Will-

Making Big Ideas Real ingham that explores the relationship between

subject-matter expertise and critical thinking

The Novice to Expert Shift: How Teachers Can Move Students Toward Mastery

Teaching Expert Thinking
Takeaways from cognitive scientist Tina Grotzer's Making Big Ideas Real research on a problem-based high school biology curriculum designed to move students toward expert-level engagement
Guidelines for implementing "invention activities" (a strategy for helping students develop structural knowledge) from the Carl Wieman Science Education Initiative at the University of British Columbia
Making Big Ideas Real

Strategies for using the Universal Design

Assessment for Learning framework to develop student expertise
Top 5 UDL Tips for Fostering Expert Learners
How Experts Differ from Novices

Overview of the nature of expert thinking from the Sourcebook for Teaching Science published by California State University, Northridge
Encyclopedia

Encyclopedia
Novices and Experts Cannot Think in the Same Ways
Blog post from Deans for Impact that explores the differences between novice and expert thinking and the implications for educators 


\section{Appendix B}

\section{Making Big Ideas Real Concepts and Resources}

\section{Concepts featured in challenge:}

- Curiosity

- Expertise

- Transfer
Concepts previewed in challenge:

- Relevance of school

- Cognitive load

- Sense of belonging

\section{Why these concepts are important in Malking Big Id leas Real:}

In Making Big Ideas Real, the focus is on designing learning experiences through which students can meaningfully and deeply engage with big ideas in a discipline over the course of a year. The SoLD concepts introduced in this challenge tie directly to this goal. In order for students to meaningfully and deeply engage with a big idea across a year, they need to be able to develop deep understanding and expertise within a discipline and be able to transfer their knowledge across learning contexts, whether that is within lessons and units, from one year to the next, or to their experiences outside of the classroom. Furthermore, designing learning experiences that resonate with students and elicit their curiosity can help them understand the relevance of the content and contribute to their sense of belonging in the classroom. It is also important when designing learning experiences to consider how to manage the cognitive load by minimizing distractions and extraneous information, such that students can focus on the deep underlying conceptual and structural knowledge that is central to the discipline.

\section{Featured Strategies:}

- Introduce the same information multiple times in varied contexts. This encourages transfer by preventing knowledge from becoming bound to a single content area, and has the potential to engage students who may have greater interest or a stronger skill set in one context versus another.

- Incorporate opportunities for "productive uncertainty." Encountering puzzles or areas of disagreement can motivate students to engage in the disciplinary practices of argumentation and explanation. To prevent students from feeling overwhelmed or discouraged, keep the aspects of uncertainty bounded in scope -- for instance, ask students to evaluate and decide between several alternative methods for data analysis. 


\section{Appendix B (continued)}

- Encourage students to engage emotionally -- not just rationally -- with what they are learning. In addition to helping students connect with the material, emotions support transfer by directing a learner's attention to the appropriate contexts for applying information. Try starting a lesson with an emotionally evocative image or example, or invite students to reflect on the emotional response they may be having to a learning experience.

\section{Connections to Adolescent Development and Sociopolitical and Historical}

\section{Contexts:}

Key takeaways:

- Brain development in middle-to-late adolescence enables higher-order thinking and the integration of concepts. Students at this age have a greater capacity for conceptual understanding, creative thinking, and exploring new scenarios and worldviews beyond their immediate context. Adolescents seek academic work that connects to "global social-historical realities" and evokes "deep cognitive, emotional, and behavioral engagement." Students often show a decline in motivation during the transition to secondary school, which may be due in part to a lack of perceived significance in the curriculum.

- Skills that are critical for success in the STEM disciplines also continue to improve during adolescence, including inductive and deductive reasoning as well as the capacity to construct and test hypotheses. Students perform best when they are asked to apply their reasoning skills in the context of their pre-existing knowledge.

- Low-income and BIPOC students, particularly those historically under-represented in STEM (including those with disabilities), may struggle to see themselves as capable of achievement in these disciplines. Curriculum that connects to students' lived experiences and presents examples of representative role models and/or historic or contemporary contributions by a range of cultures can increase the perception that they belong and can be successful. 